\title{
Vertical Supplementary Mesiodens Erupted with Posteroanterior Angulation: Case Report
}

\section{Betanco MAP* \\ Department of Oral Medicine, National Autonomous University of Nicaragua, Nicaragua}

*Corresponding author: Amed Paz Betanco, Research Professor Department of Oral Medicine, Faculty of Dentistry. National Autonomous University of Nicaragua, León, Nicaragua, Email: manuel.paz@fo.unanleon.edu.ni

\section{Case Report}

Volume 6 Issue 4

Received Date: October 14, 2021

Published Date: November 17, 2021

DOI: $10.23880 /$ oajds-16000316

\section{Abstract}

Introduction: Supernumerary teeth are an alteration in the number of teeth and depending on their location in the maxilla, they receive a name: mesiodens if it is close to the midline, paramolar if it is posterior to the third molar. Objective: classify a mesiodens according to its clinical and radiographic location.

Clinical case: A clinical case of a 10-year-old child is presented. Reason for consultation: abnormal tooth. Clinical and radiographic examination compatible to supernumerary tooth. We proceed to grant a classification and complete the literature review.

Conclusion: The treatment of this dental anomaly will depend on the patient's guardian and its values and beliefs; respecting the national and international parameters of medical ethics.

Keywords: Mesiodens; Dental Anomaly; Radiographic Analysis

\section{Introduction}

Hyperodontia or supernumerary teeth corresponds to an anomaly of tooth number development, where one or more teeth or additional odontogenic structures are present at 20 and 32 teeth of the normal series of primary and permanent dentition, respectively [1]. Supernumerary teeth have a prevalence ranging between 0.3 and $3.8 \%$. When the affected region is located in the midline of the palate between the two upper central incisors it is called mesiodens and this presents a prevalence of 0.15 to $1.9 \%$ in the general population [2].

There are several theories about the etiology of supernumerary teeth, however, until now its origin is unknown. The first theory is that of Atavism, which consists in explaining the supernumeraries as an expression of a trait of our ape-like ancestors, who possessed a greater number of teeth. The second is that of the anomalous division of the dental germ (dichotomy). The third is the theory of the hyperactivity of the dental lamina, which consists in the alteration of growth plus a localized focal hyperactivity of the dental lamina. This is the most widely accepted theory for the development of supernumerary teeth; however, it is also attributed to factors such as inheritance and family tendency and to some factors of the environment [3].

\section{Supernumerary Teeth are Classified as Follows:}

a) According to the form: supplementary or rudimentary. The latter include conical, tuberculated and molariform types.

b) Depending on the location: mesiodens, paramolar or distomolar [4].

The reported clinical complications of a mesiodens include: delayed eruption of the permanent incisors, diastema in the midline, axial rotation or inclination of the permanent 
incisors, resorption of the adjacent roots, root anomalies, formation of cysts, intraoral infections and pulpitis in the mesiodens [5].

\section{Clinical Case}

Male patient of 10 years of age, without systemic antecedents, of scarce economic resources and coming from a rural area of western Nicaragua goes to a private oral medicine clinic accompanied by his father, who reports observing an abnormal tooth in his son.

To the intraoral examination, mixed dentition is observed (Figure 1), a meticulous examination is carried out to evaluate present pieces, parts to be exfoliated and pieces to be erupted. It is observed that at the level of the midline there is a piece adjacent to the 1.1, with similar shape and appearance to the neighboring piece, however, the vestibular face erupted towards the palate and the palatinal cingulate is palpable at the vestibular level (Figure 2).

The exposure of a panoramic radiograph was oriented, however, due to the precarious economic situation of the family, a periapical radiograph was exposed (Figure 3) where a dental piece with a pulp chamber and root canal is observed, a single root that acquires a sinuous shape. Apical level with closed apex if we compare it with the roots of pieces 1.1 and 2.1 that still have the apices open.

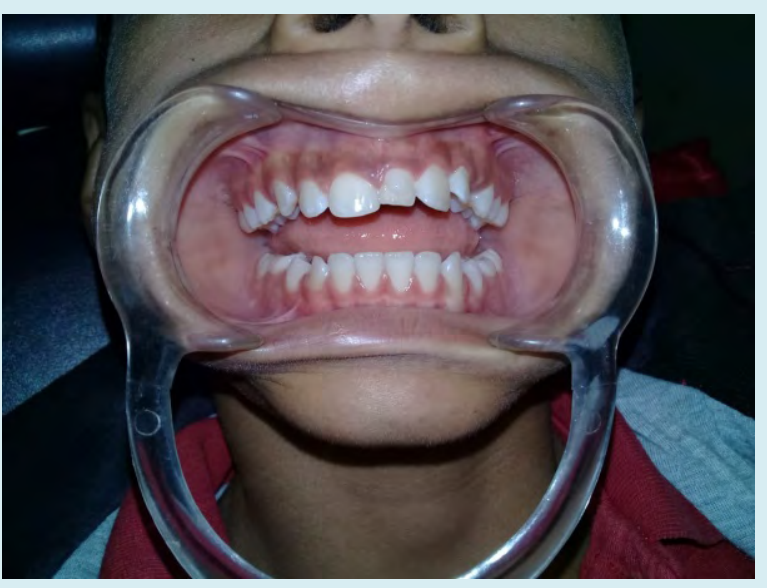

Figure 1: Panoramic view of the patient's mixed dentition.

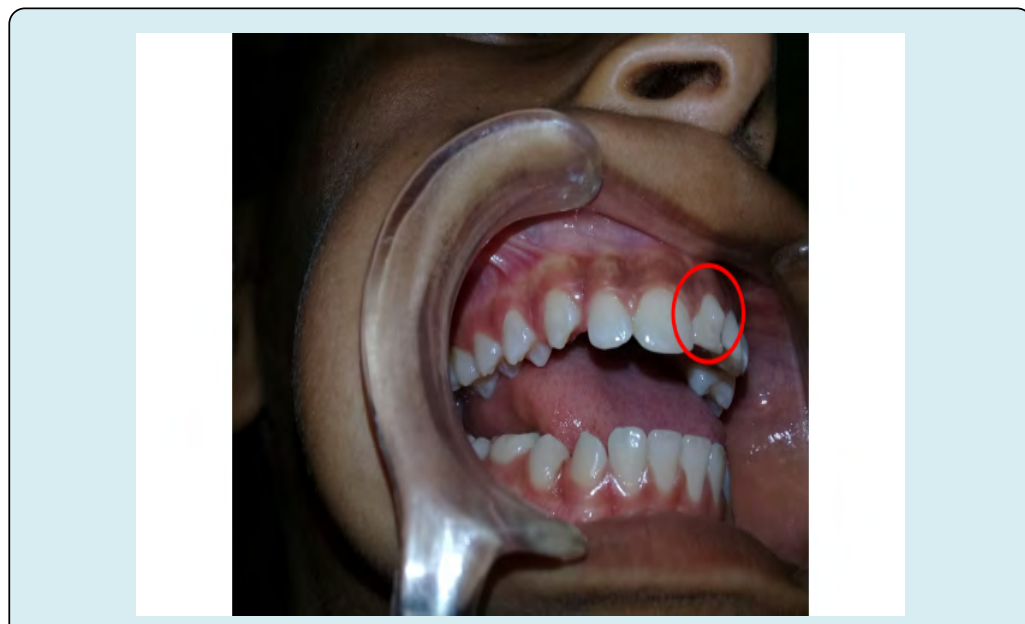

Figure 2: Lateral view of the palatinal cingulate of the mesiodens. 


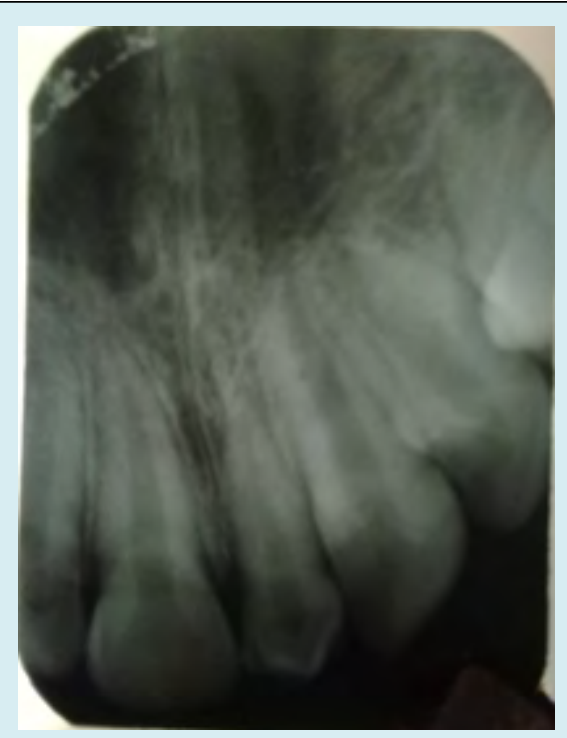

Figure 3: Periapical radiograph of the supernumerary tooth.

\section{Discussion}

Sebastián, et al. [6] report that supernumerary teeth are diagnosed by clinical examination and conventional radiological studies such as orthopantomography, occlusal radiography and periapical images, it should be considered that the use of these auxiliary elements of the diagnosis will be determined according to the particular case of each individual and therefore of the treatment therapy to be used.

For this case, an exhaustive clinical examination was used together with the retroalveolar radiographic study. This method was used because the patient comes from families with very limited economic resources that do not have access to a health system that provides these special services.

Although it is true, intraoral retroalveolar studies are inexpensive, but it is the first line of diagnosis for the general dentist or specialist because by making detailed and pertinent analyzes, a fairly deep understanding of the normal structures or alterations of the oral complex is achieved. For this case, an exhaustive clinical examination was used together with the retroalveolar radiographic study. This method was used because the patient comes from families with very limited economic resources that do not have access to a health system that provides these special services.

Although it is true, intraoral retroalveolar studies are inexpensive, but it is the first line of diagnosis for the general dentist or specialist because by making detailed and pertinent analyzes, a fairly deep understanding of the normal structures or alterations of the oral complex is achieved.
Once the stomatological study was contrasted with the imaging study, it can be said that the supernumerary tooth presented by this individual is a mesiodens due to its anatomical location, it is located in the midline between both maxillary incisors and is located interdentally, with a vertical orientation and to the paying attention to the shape of this can be said to be supplementary due to its marked similarity to the adjacent piece. The angulation of this tooth is posteroanterior because, as seen in Figure 2, the posterior face of the supernumerary tooth is oriented towards the labial vestibule of the patient.

In this case presented, the mesiodens found is supplementary due to its anatomical similarity with the upper central incisors, however, in the study carried out by Jammal \& Silva [7] in which they analyzed panoramic radiographs of 1038 patients, that the most prevalent supernumerary teeth were rudimentary conics in $35 \%$ of the developing population.

One of the treatment alternatives for cases where there are mesiodens in the maxilla is the use of fixed orthodontic appliances after the extraction of the supernumerary tooth [2]. Among the complications in the post-treatment of dental extraction will depend on some factors such as the size of this supplementary tooth, the age at which the patient proceeds to perform this procedure and the skills of the professional for the surgical management of presenting. any intraoperative complication [5].

Orthodontic treatment is not accessible in Nicaragua for people with limited economic resources because this type of 
dental treatment is not a medical service offered in the Public Health system, here priority is given to children, pregnant women, maxillofacial trauma emergencies and prevention and management of tumor lesions.

The different orthodontic treatments are offered in the private part of dentistry, and the costs range in more than two thousand dollars, which includes both the placement of the fixed orthodontic appliances, monthly operative controls, use of creams and mouthwashes, brushes orthodontics, orthodontic waxes, among other expenses that the patient must meet according to each particular case.

Regarding the site there is not much information in the literature, but it serves as a reference for academic issues and radiological description as described by Sebastián C, et al. [6]. In this patient, it was not possible to carry out the surgical treatment of the supplementary piece due to the negative position of the minor's family, who did not authorize said procedure due to personal beliefs.

As responsible and knowledgeable doctors of the tumor complications of this type of dental retentions, all the medical explanations of the behavior of the non-treatment of these supplementary teeth were given. At all times the autonomy of the patient was respected within the framework of bioethics and its principles. In this way, the provisions of the General Health Law of Nicaragua and the International Laws of Medical Bioethics were complied with.

Another of the treatment alternatives proposed to the patient's parents were the extraction of the supplementary tooth, waiting for the child to comply with the eruptive process of all the permanent teeth and monitoring the closure of the natural diastema and if this closure could not be achieved with resin or porcelain veneers for the aesthetic area of the smile.

The prevalence of mesiodens in Nicaragua is unknown and no studies have been conducted to contrast the complications of these. The means of diagnosis through images are expensive and this makes it difficult to carry out epidemiological studies on a greater number of individuals.

\section{Conclusion}

The clinical management of a supernumerary tooth is given in our country by multiple factors that influence the resolution of the main complaint of the individual who suffers.

\section{References}

1. Fuentes R, Álvarez G, Garay I, Arias A, Dias F (2018) Supplementary supernumerary teeth in a partially dentate adult patient: Case report. Int J Morphol pp: 478482.

2. Giovanetti K, Sigua Rodriguez E, Pacheco L, Figueiredo E, Albergaria Barbosa J (2016) Mesiodens. Case report. Rev Fac Odontol Univ Antioq 28(1): 210-219.

3. Villavicencio J, Hernández J, Medina S (2015) Clinical variations of double mesiodens: a review and report of cases. Rev Fac Odontol Univ Antioq 27(1): 216-227.

4. Palanisamy V, Rao A, Ongole R, Chacko V (2016) Mandibular mesiodens-A rare case report. Journal of Oral and Maxillofacial Surgery, Medicine, and Pathology 29(2): 163-165.

5. Mufeed A, Hafiz A, Ashir K, Ahmed A, Reshma V (2015) Clinical consequence of mesiodens-A case series. Journal of Oral and Maxillofacial Surgery, Medicine, and Pathology 28(3): 259-262.

6. Sebastián CC, Izquierdo B, Gutiérrez C, Aso A (2016) Supernumerary teeth: essential keys for an adequate radiological report. Revista Argentina de Radiología.

7. Jammal N, Silva R (2015) Prevalence of supernumerary teeth in a mexican sample. Mexican Journal of Orthodontics 3(2): 88-91. 